doi https://doi.org/10.29327/224874.3.1-3

\title{
a afetividade e seu desenvolvimento na educação infantil: reflexões linguístico-dialógicas
}

${ }^{1 \bullet}$ Wilder K.F.S., ${ }^{2}$ Márcia R.S.J., ${ }^{3}$ Rafael M.G., ${ }^{4}$ Lucas F.L.

1 universidade federal da paraíba

2 universidade federal da paraíba

3 universidade federal do rio de janeiro

4 universidade federal da paraíba

• e-mail de contato principal: wildersantana92@gmail.com

resumo

foi nosso objetivo analisar de que maneira as professoras da creche trabalham com as crianças, buscando responder à seguinte questão: de que forma os alunos de uma creche em Pombal/PB são estimulados a explorar os campos da afetividade no processo de aprendizagem? Para tanto, realizamos um estudo teórico-analítico sobre a influência da afetividade nos processos de ensino e aprendizagem, averiguando como algumas professoras da educação infantil constroem relações afetivas em suas atividades cotidianas, espontâneas ou intencionais. Utilizamos para tal questionários semiabertos, aplicados em quatro professoras, posteriormente analisados pela técnica de análise de discurso. Inferimos que a relação professor/aluno das depoentes é pautada tanto pelas condições físicas de um espaço capaz de atender as necessidades da criança, como também, pela capacidade de estabelecer diálogos, desenvolver a empatia para melhor compreender a linguagem emocional da criança e afetá-la sem as marcas de uma relação autoritária e coercitiva, mas sim pelas marcas da alegria e entusiasmo que criam condições para a criança se desenvolver mais rapidamente e integralmente.

palavras-chave: afetividade; psicologia da educação; educação infantil.

\section{como citar este artigo}

Santana, W. K. F., Junqueira, M. R. S., Garcia, R. M., \& Lima, L. F. (2021). A afetividade e seu desenvolvimento na educação infantil: reflexões linguístico-dialógicas. Revista Interdisciplinar em Estudos de Linguagem, 3(1), 32-40, doi https://doi.org/ 10.29327/224874.3.1-3 


\section{introdução}

Os estudos realizados, a partir de autores como Wallon, Piaget, Vygotsky e outros pesquisadores que estudam a dimensão da afetividade e sua significativa influência para os processos de ensino e aprendizagem apontam que quanto mais a criança for afetada positivamente, mais ela se desenvolve integralmente. Entendemos por afetação todas as ações que envolvem interações entre as pessoas e estimulam as capacidades psicomotoras, como esquema corporal, lateralidade, coordenação motora, linguagem, entre outros (Cohen, 2014).

Nesse sentido, nossa pesquisa consiste numa tentativa de apresentar reflexões sobre a afetividade, enquanto ação intencional, e sua relação direta com a aprendizagem, com intuito de colaborar com o trabalho de professores da primeira etapa da educação infantil. Compreender o significado da afetividade e sua relação com o processo de aprendizagem da criança, considerando que em qualquer circunstância, o primeiro caminho para a conquista da atenção do aprendiz é a maneira pela qual o afetamos positivamente, é primordial para este processo. Dessa forma os resultados deste estudo poderão sugerir que as relações pautadas no afeto positivo facilitam os processos de ensino aprendizagem e são imprescindíveis para o desenvolvimento integral da criança.

Nosso aporte teórico se concentra, dentre outros autores, em clássicos como Vygotsky (2003) e Wallon (2007), dialogando também com demais pesquisas realizadas na área da psicomotricidade humana (Cunha, 2008a, 2008b; Cohen, 2014; Garcia \& Pereira, 2019). Interessa-nos entender como os processos educacionais afetivos incidem na construção e formação das aprendizagens nas crianças, discutindo como esse diálogo constante traz resultados significativos para seus aspectos psicossociais. É no contato com o outro que desenvolvemos as emoções e construímos novos conhecimentos, sendo assim, os vínculos afetivos socialmente construídos são bases para caracterização do nosso comportamento ao longo da vida.
Atualmente, um dos autores deste trabalho compõe o quadro de professores da "Creche ABC1", no interior do Estado da Paraíba, e tem-se percebido que nas reuniões de equipe o tema afetividade, quando mencionado, ainda é debatido de maneira superficial, apenas como uma expressão de carinho e ternura. Os planejamentos estão voltados para elaboração de atividades e ações que visam atender o intelecto, dissociando a cognição da afetividade. Essa percepção nos inquietou ao ponto de formulamos a seguinte questão problema: de que forma os alunos da instituição de ensino infantil "Creche ABC", em Pombal/PB, são estimulados a explorar os campos da afetividade no processo de aprendizagem?

Portanto, é de nosso objetivo geral analisar a maneira com que as professoras da creche trabalham com as crianças à luz da problemática acima. Para tanto, realizamos um estudo teórico-analítico sobre a influência da afetividade nos processos de ensino e aprendizagem; averiguamos como algumas professoras da educação infantil constroem relações afetivas em suas atividades cotidianas, espontâneas ou intencionais; e problematizamos como a afetividade pode influenciar no processo de aprendizagem da criança através da relação professor/aluno.

Para os fins teóricos, temos como subsídios os fundamentos de Henri Wallon (1986; 1995; 2007), no que tange à importância da afetividade, assim como seus interlocutores. Os dados foram construídos a partir de um questionário, seguido de perguntas, previamente elaboradas que permitem ser exploradas de maneira espontânea (descreveremos melhor esse processo na seção metodológica). A seguir, discorremos sobre os conceitos de afetividade e processos de aprendizagem pela criança, fundamentais para nortear nossas investigações e análises e delinear o contorno deste estudo em questão.

\section{a afetividade e os processos de ensino e aprendizagem da criança}

O estudo sobre a afetividade nos leva a compreender sua relação com o processo de aprendizagem da criança. Sobre essa temática, a teoria de Wallon traz contribuições

\footnotetext{
1 Por motivos éticos, não mencionamos o nome verdadeiro da instituição. Todos os termos aqui empregados são fictícios, com o intuito de garantir o anonimato e sigilo dos envolvidos na pesquisa.
} 
que nos permitem entender a afetividade como um domínio funcional tão importante quanto $\mathrm{o}$ da inteligência, que assumem funções bem definidas, porém indissociáveis, possibilitando à criança atingir níveis de evolução cada vez mais elevados (Wallon, 2007).

A afetividade é, portanto, um conjunto funcional que emerge do orgânico e adquire um status social a partir da relação com o outro, assumindo uma dimensão fundamental na formação da pessoa completa, referindose à capacidade e disposição do ser humano de ser afetado pelo mundo externo e interno, por sensações ligadas às tonalidades agradáveis ou desagradáveis.

A noção de pessoa apresentada por Wallon (2007) aponta para uma síntese dos conjuntos funcionais (afetivo, motor e cognitivo) e para integração dinâmica entre o orgânico e o social. Nesse sentido, assim como a afetividade, a cognição também é um elemento fundamental na psicogênese da pessoa completa, sendo seu desenvolvimento relacionado às bases biológicas e suas constantes interações com o meio. A teoria walloniana é contrária à compreensão do humano de forma fragmentada.

É contra a natureza tratar a criança fragmentariamente. Em cada idade, ela constitui um conjunto indissociável e original. Na sucessão de suas idades, ela é um único e mesmo ser em curso de metamorfoses. Feita de contrastes e de conflitos, a sua unidade será por isso ainda mais susceptível de desenvolvimento e de novidade (Wallon, 2007, p. 198)

Essa posição implica repensarmos as práticas educacionais, que muitas vezes trata a criança de maneira coisificada, e não como sujeito de direito, que possui uma natureza singular, capaz de sentir e pensar o mundo de um jeito muito próprio. A criança deve ser entendida de maneira integral, considerando as fases do seu desenvolvimento e toda sua bagagem emocional e cultural (Wallon, 2007; Rodrigues, 1976).

Atualmente, algumas pesquisas se inclinam a debater sobre o caráter de violência simbólica ao qual as crianças são submetidas ao terem seu processo de autonomia desvalorizados pelo saber adultocêntrico de seus pares verticais cronologicamente, tais como propõem Couto
Junior, Pocahy \& Oswald (2018) e Garcia (2020). Neste processo, muitas vezes a afetividade é negada e negligenciada como importante ferramenta para potencializar a aprendizagem, distanciando o aluno do real objetivo do processo de desenvolvimento.

A afetividade e a cognição alternam sua atuação em todos os estágios da vida humana, porém esses conjuntos exercem influência relevante durante o processo de sua prevalência, ou seja, essa alternância de domínios funcionais não exclui a presença dos conjuntos não dominantes, pois estes continuam exercendo influência uma ao outro, contribuindo para o desenvolvimento integral do ser. É importante entender que o conjunto afetivo reúne funções responsáveis pelas emoções, sentimentos e paixões, influenciando o meio social e afetando a esfera cognitiva do sujeito. Neste sentido, Gonçalves (2003) enfatiza:

O recém-nascido não tem ainda outras formas de se comunicar com o outro, que não a emoção [...] Cada movimento, cada expressão corporal dessa criança, acaba por receber um significado, atribuído pelo outro, significado esse do qual ela se apropria. Uma criança que chora porque seu estômago dói de fome, não chora inicialmente para alguém vir alimentá-la, mas chora por causa da dor. Ao receber a atenção que necessita, vai construindo os significados de cada ação sua (pp. 14-15).

No princípio, a emoção é persistente e propagadora. Tem um "poder totalizador" sobre o comportamento (Wallon, 1995). Durante o desenvolvimento, na interação com a realidade mediada pelas pessoas que a rodeiam, a criança vai apropriando-se da linguagem e de formas sociais de comportamento que passam a interagir com a emoção, transformando-a a ponto de já não mais dominar o seu comportamento. Agora, o que passa a predominar é a complexa relação que vai se estabelecendo entre a emoção e as outras funções psíquicas (Wallon, 1995; Rodrigues, 1976). A partir dessas reflexões, podemos pensar no papel da creche enquanto instituição de educação básica infantil que acolhe a criança ainda nos seus primeiros meses de vida. Na perspectiva de Rizzo, "A creche existe para exercer, pela família os cuidados básicos de saúde e educação indispensáveis ao bem-estar da criança a partir dos três meses de idade, 
cuidando de sua segurança física e emocional, durante o horário de afastamento de seus pais" (Rizzo, 2006, p. 46).

Nos espaços da creche toda ação deve ser pensada para melhor atender as necessidades da criança, que está formando sua personalidade e precisa ser afetada intencionalmente. Para isso é fundamental que o educador conheça a criança e elabore ações capazes de suprir as especificidades de cada fase do seu desenvolvimento. Assim, em termos afetivos, "O modelo de educação que funciona é aquele que começa pela necessidade de quem aprende e não pelos conceitos de quem ensina. Ademais, a prática pedagógica para afetar o aprendente deve ser acompanhada por uma atitude vicária do professor" (Cunha, 2008b, p. 63).

Logo, o professor cumpre o seu papel, quando afeta a criança a partir de suas necessidades, quando é capaz de promover boas emoções e conquistar sua atenção, despertando-lhe o desejo de aprender com entusiasmo e alegria.

As reações emocionais exercem uma influência essencial e absoluta em todas as formas de nosso comportamento e em todos os momentos do processo educativo. Se quisermos que os alunos recordem melhor ou exercitem mais seu pensamento, devemos fazer com que essas atividades sejam emocionalmente estimuladas. A experiência e a pesquisa têm demonstrado que um fato impregnado de emoção é recordado de forma mais sólida, firme e prolongada que um feito indiferente (Vygotsky, 2003, p. 121).

As emoções abrem os campos mais profundos da mente, acionam a memória de longo prazo de maneira intensa, por isso é importante compreender o quanto $O$ afeto positivo é impactante e sua ação é capaz de acelerar o processo de aprendizagem da criança. Nesse sentido, a creche assume papel relevante, pois o professor da educação infantil lida com fases do desenvolvimento da criança, onde suas expressões são movidas basicamente por emoções.

o trabalho na creche exige que o professor tenha sensibilidade e disponibilidade, para permitir-se ser tocado pela intensidade emocional das crianças, acolhendo-as e entendendo-as como forma de verbalização que ainda nesta idade é tida como principiante, ou seja, incipiente (Roncarati, 2012, p. 46).

É esperado que as crianças de 0 a 3 anos se expressem através das emoções, pois é sua primeira forma de comunicação até dominar a linguagem. São as emoções que assumem posição de destaque nas suas relações com o mundo.

Há professores, mesmo com pouquíssimos recursos, que afetam tanto que são capazes de transformar suas aulas em dínamos de inteligências, mesmo recitando o catálogo telefônico. Pode ser um exagero usar o catálogo como metáfora, mas na verdade, na memória, o que mais conservamos são as coisas que nos afetam, para o bem ou para o mal (Cunha, 2008b, p. 69).

Os vínculos afetivos positivos que se estabelecem entre professor e aluno independem do conhecimento teórico que o professor detém, ou dos mais sofisticados recursos pedagógicos. Esta relação a qual nos referimos fundamenta-se na empatia, no respeito e reconhecimento que se estabelecem na convivência diária entre os sujeitos envolvidos.

- professor autoritário, o professor licencioso, o professor competente, sério, o professor incompetente, irresponsável, o professor amoroso da vida e das gentes, o professor mal amado, sempre com raiva do mundo e das pessoas, frio, burocrático, racionalista, nenhum deles passa pelos alunos sem deixar sua marca (Freire, 1996, p. 96).

O fato é que nossa memória pode ser marcada por afetos positivos ou negativos e sobre essa questão é possível refletir a respeito das práticas do professor de educação infantil em creche, ou seja, como as ações pedagógicas são elaboradas para afetar a memória das crianças positivamente. O afeto através dos comportamentos amorosos acelera o desenvolvimento integral do ser, já os afetos negativos, geralmente presos a métodos impositivos e dominadores, são capazes de produzir marcas danosas e indeléveis na memória de longo prazo, causando bloqueios que impedirão o desenvolvimento da aprendizagem. Desse modo, "O espaço não é primitivamente uma ordem entre as coisas, é antes uma qualidade das coisas em relação a nós próprios, e nessa relação é grande o papel da afetividade, da pertença, do aproximar ou do 
evitar, da proximidade ou do afastamento" (Wallon, 1986, p. 33).

São as marcas que imprimimos nos espaços onde ocupamos que determinarão a qualidade do ambiente e, portanto, a maneira pela qual afetamos as crianças. Neste sentido, o professor da educação infantil é responsável por tornar a sala de aula em um ambiente alegre, de cooperação, que estimule a aprendizagem de maneira prazerosa e entusiástica. $\mathrm{Na}$ concepção construtivista de Piaget, este afirma:

Eis porque a criança se socializa mais, ou de modo diferente, com os seus semelhantes do que com os adultos. Onde a superioridade do adulto impede a discussão e a cooperação, o companheiro dá ocasião a essas condutas sociais, que determinam a verdadeira socialização da inteligência. De maneira oposta, onde a igualdade dos companheiros impede a questão ou a interrogação, o adulto está à disposição para responder (Piaget, 1959, p. 95).

Todas essas reflexões nos levam a pensar sobre o quanto a afetividade é primordial para a criança se desenvolver plenamente e o quanto a instituição creche tem a responsabilidade de promover uma educação fortalecida pelas relações de cooperação, onde além de uma relação de troca, o professor possa atuar sempre compreendendo as peculiaridades dos seus alunos. "As crianças possuem uma natureza singular, que as caracteriza como seres que sentem e pensam o mundo de um jeito muito próprio" (RCNEI, 1998, p. 21). Esta singularidade precisa ser considerada se realmente quisermos realizar uma educação de qualidade.

\section{procedimentos metodológicos}

Quanto aos procedimentos metodológicos, a pesquisa sobre o tema "A afetividade e desenvolvimento cognitivo na Educação Infantil" é de cunho exploratório, de modo a dar continuidade e aprofundamento ao fenômeno estudado. Visamos com isso detalhar informações sobre o tema investigado no intuito de familiarizar-se ou obter nova percepção do fenômeno estudado. Os procedimentos da pesquisa bibliográfica permitiram desenvolver reflexões sistematizadas a respeito do tema em evidência, tomando como base pesquisas em artigos e livros de autores reconhecidos.
A referida pesquisa tem enfoque qualitativo, pois traduz os resultados da pesquisa em conceitos e ideias, cujo desenvolvimento se dá na compreensão detalhada dos significados e características situacionais apresentadas pelos entrevistados, em lugar da produção de medidas quantitativas de características ou comportamentos (Richardson, 2008).

Realizamos uma pesquisa de campo com a finalidade de obter informações e/ou conhecimentos relacionados ao problema no qual buscamos respostas. Foram envolvidos nesta pesquisa quatro professoras da educação básica infantil de uma creche na cidade de Pombal/PB. Todas residem no mesmo município, possuem perfil profissional de graduado em pedagogia e o tempo de trabalho nesta instituição é de 3 anos. As docentes tiveram seus nomes preservados, garantindo seu anonimato. Apresentamos os resultados e decidimos chamá-las de P1, P2, P3, P4.

Foi utilizado como instrumento de coleta um questionário semiestruturado, por meio de questões subjetivas com a finalidade de verificar a compreensão dos participantes sobre a importância da afetividade para o desenvolvimento cognitivo da criança. O questionário continha questões sobre a importância da afetividade para o desenvolvimento cognitivo da criança, ou seja, qual a influência da afetividade para a aprendizagem do aluno.

Para a análise de dados, recorremos à técnica proposta por Bicudo (2011). Dividida em quatro etapas, esta técnica primeiro seleciona todo o material, delimita categorias chave para discussão, prolonga suas interpretações a partir do referencial teórico e a partir daí desenvolve suas inferências em diálogo com seu aporte bibliográfico. Esperase, com isso, evidenciar sentidos e unidades de significado a partir das necessidades do objeto do estudo, estabelecendo assim redes interligadas de conexões epistemológicas e empíricas.

\section{interpretação e análise dos dados}

Mediante os dados colhidos através dos questionários realizados com as professoras de uma creche na cidade de Pombal-PB, pôde-se obter de forma mais precisa a compreensão das mesmas acerca da relação entre afetividade e aprendizagem. Deste 
modo, observaremos as informações que foram colhidas para a análise do quadro a seguir.

Quadro 1

Contribuições da afetividade para a melhoria do ensino na educação infantil

\section{Você acredita que a afetividade pode contribuir para melhoria do ensino na educação infantil? Por que?}

\begin{tabular}{|c|c|}
\hline P1 & $\begin{array}{l}\text { Sim, pois é através das relações } \\
\text { afetivas positivas que a criança } \\
\text { aprende e desenvolve conhecimentos } \\
\text { que irão contribuir na sua trajetória } \\
\text { escolar. }\end{array}$ \\
\hline P2 & $\begin{array}{l}\text { Sim, acredito que a afetividade } \\
\text { positiva entre professor - aluno seja } \\
\text { um fator importante que motiva a } \\
\text { criança a construir sua aprendizagem, } \\
\text { assim como facilita o trabalho do } \\
\text { educador, pois quando há um bom } \\
\text { relacionamento entre ambos, e o aluno } \\
\text { percebe que o docente acredita na } \\
\text { sua capacidade de se desenvolver, } \\
\text { sentem-se mais motivados, o que } \\
\text { contribui de forma significativa para o } \\
\text { processo ensino - aprendizagem. }\end{array}$ \\
\hline P3 & $\begin{array}{l}\text { Sim. A crianças precisa se sentir } \\
\text { segura para a prender e se } \\
\text { desenvolver, dessa maneira, é a partir } \\
\text { da relação de ternura e carinho que o } \\
\text { professor conseguirá conquistar a } \\
\text { confiança do aluno e estimular o seu } \\
\text { desenvolvimento pleno. }\end{array}$ \\
\hline P4 & $\begin{array}{l}\text { Sim, acredito que as relações afetivas } \\
\text { positivas estimuladas em sala de aula, } \\
\text { são fundamentais para a criança se } \\
\text { desenvolver plenamente, pois } \\
\text { aprendem a partir de suas interações } \\
\text { com o outro e com o meio de maneira } \\
\text { geral, sendo assim, a afetividade ao } \\
\text { abrir campo para que a criança } \\
\text { desenvolva-se integralmente, contribui } \\
\text { diretamente para a melhoria do ensino } \\
\text { na educação infantil. }\end{array}$ \\
\hline
\end{tabular}

Fonte: elaboração própria a partir das respostas das professoras

Para as professoras, afetividade positiva contribui para a melhoria do ensino na educação infantil pelo fato de estar diretamente ligada ao desenvolvimento integral da criança, neste sentido o afeto é o meio facilitador, capaz de acelerar o processo de aprendizagem e consequentemente promover uma educação de qualidade.

Em qualquer circunstância, o primeiro caminho para a conquista da atenção do aprendiz é o afeto. Ele é um meio facilitador para a educação. Irrompe em lugares que, muitas vezes, estão fechados às possibilidades acadêmicas. Considerando o nível de dispersão, conflitos familiares e pessoais e até comportamento agressivo na escola, hoje em dia, seria difícil encontrar algum outro mecanismo de auxílio ao professor mais eficaz (Cunha, 2008b, p. 51).

Neste aspecto, compreende-se que o afeto se assemelha ao combustível, capaz de produzir qualidade na educação infantil, pois supera barreiras e atravessa as fronteiras da mente humana, sendo possível levar a criança a construir novos significados e efetivar a aprendizagem. Segundo Davis \& Oliveira (1990, p. 84) "O afeto pode, assim, ser entendido como a energia necessária para que a estrutura cognitiva passe a operar".

A aprendizagem escolar depende, basicamente, dos motivos intrínsecos: uma criança aprende melhor e mais depressa quando se sente querida, está segura de si e é tratada como um ser singular [...] Se a tarefa escolar atender aos seus impulsos para a exploração e a descoberta, se o tédio e a monotonia forem banidos da escola, se o professor, além de falar, souber ouvir e se propiciar experiências diversas, a aprendizagem infantil será melhor, mais rápida e mais persistente (Rodrigues, 1976, p. 174).

Os motivos da criança para aprender são os mesmos motivos que ela tem para viver. Eles não se dissociam de suas características físicas, motoras, afetivas e psicológicas do desenvolvimento. As atividades desenvolvidas em sala de aula, por meio da afetividade devem proporcionar experiências diversas, pois a criança aprende, a partir de sua relação com o professor, que deve assumir uma postura respeitosa com o aluno, estabelecendo relação de diálogo e troca, aprendendo também com o meio, explorando o que está à sua volta, de maneira alegre e entusiástica, fazendo conexões quando o professor atende suas necessidades. Logo, a afetividade deve estar implícita em toda forma de ensinar, já que em toda e qualquer atividade é possível ser afetuoso. 
Para Piaget (1983), as crianças só são capazes de aprender o que estão preparadas a assimilar, cabendo aos professores aperfeiçoar o processo de descoberta das mesmas. As diversas diferenças notadas entre as crianças reforçam as ideias das "estruturas operatórias", que caracterizaram tal pensamento científico. Convicto de que o desenvolvimento intelectual ocorre em estágios, Piaget aborda temas como as "estruturas operatórias" e demonstra o "sujeito epistêmico" como o conjunto de características comuns a todas as crianças de um mesmo estágio de desenvolvimento (Piaget, 1983).

A Escola Nova, para Piaget, utiliza-se de novos meios para educar e critica o ensino onde "o professor dita e o aluno copia e repete", a chamada "educação bancária", de Paulo Freire (1996). A ideia piagetiana de interação demonstra que a capacidade cognitiva humana nasce e se desenvolve, não vem pronta, marcando assim oposição ao behaviorismo ao afirmar que o conhecimento tem origem na interação "sujeito-objeto".

As relações afetivas entre professor/ aluno são imprescindíveis para o processo de aprendizagem, devendo ser construídas a partir do comportamento respeitoso do educador, que deve manter-se sempre disposto a dialogar com a criança, desenvolvendo um olhar igualitário e compreensivo, pois é através desse fortalecimento de vínculos afetivos, que tornase possível despertar na criança o prazer de aprender. Assim como coloca Roncarati (2012, p. 46) "O trabalho na creche exige que o professor tenha sensibilidade e disponibilidade, para permitir-se ser tocado pela intensidade emocional das crianças". Assim, o próximo quadro tratará diretamente sobre a relação que a afetividade mantém com o processo de aprendizagem.
Quadro 2: Relação entre afetividade e aprendizagem

\section{Na sua opinião, a afetividade mantém relação com a aprendizagem? Como?}

\begin{tabular}{|c|c|}
\hline P1 & $\begin{array}{l}\text { Sim, considerando que o professor } \\
\text { não ensina somente os conteúdos, } \\
\text { como também ensina a amar, a } \\
\text { respeitar e tudo isso se dá através } \\
\text { da afetividade. }\end{array}$ \\
\hline P2 & $\begin{array}{l}\text { Sim, uma vez que a afetividade } \\
\text { está presente em todas as áreas } \\
\text { da vida do ser humano e é, de } \\
\text { fundamental importância para o } \\
\text { desenvolvimento da personalidade } \\
\text { da criança, pois quando estamos } \\
\text { inseridos num ambiente afetuoso } \\
\text { somos mais motivados a aprender } \\
\text { e consequentemente é possível } \\
\text { desenvolver-se integralmente. }\end{array}$ \\
\hline P3 & $\begin{array}{l}\text { Sim, a afetividade está } \\
\text { intimamente ligada aprendizagem, } \\
\text { pois a criança aprende mais } \\
\text { rápido quando se sente envolvida } \\
\text { pelas atitudes de carinho do seu } \\
\text { professor, o ambiente afetuoso, } \\
\text { tranquilo, na minha opinião gera } \\
\text { boas emoções e cria condições } \\
\text { para o aluno desenvolver-se mais } \\
\text { rapidamente. }\end{array}$ \\
\hline P4 & $\begin{array}{l}\text { Sim. A criança ao vivenciar } \\
\text { experiências harmoniosas, onde o } \\
\text { meio e sua relação com o } \\
\text { professor a faz sentir-se segura e } \\
\text { acolhida, terá mais facilidade de } \\
\text { aprender, pois a confiança é } \\
\text { fundamental para a conquista da } \\
\text { atenção do aluno, acredito que } \\
\text { essa aproximação despertará na } \\
\text { criança, o desejo de aprender com } \\
\text { entusiasmo e motivação. }\end{array}$ \\
\hline
\end{tabular}

Fonte: elaboração própria a partir das respostas das professoras

Todas as professoras enfatizaram que a afetividade mantém relação com a aprendizagem e que esta relação se dá pelo envolvimento da criança com o professor e com o meio. As reflexões das professoras vão de encontro com o pensamento de Vygotsky (2003, p. 121), quando diz que "A experiência e a pesquisa têm demonstrado que um fato impregnado de emoção é recordado de forma mais sólida, firme e prolongada que um feito indiferente". 
Vygotsky particulariza o processo de ensino e aprendizagem, colocando aquele que aprende e aquele que ensina numa relação interligada, entrando assim numa nova teoria, a da mediação como um pressuposto da relação eu-outro social. Essa relação não se dá necessariamente através da interação entre duas pessoas, mas também pela possibilidade de interação com signos, símbolos, culturas e objetos. O ser humano constitui-se enquanto tal na sua relação com o outro, sendo a aprendizagem relacionada ao desenvolvimento desde 0 nascimento, tornando-se assim a principal causa para o devido desenvolvimento do ser (Vygotsky, 2003).

De maneira enriquecedora, as professoras apresentaram condições importantes para uma convivência afetuosa no ambiente educacional, que devem contribuir para a aprendizagem e desenvolvimento da criança.

O cuidado com o aluno vai muito além de dar beijinho, elogiar e acarinhar. Muitas vezes o afeto é demonstrado de forma contraria: quando o professor é severo. Se ele é justo e chama a atenção de forma respeitosa, o aluno passa a admirá-lo e busca não o decepcionar [...] Alunos que se relacionam e se desenvolvem bem são aqueles que se sentem acolhidos, valorizados por seus talentos e que lidam bem com seus sentimentos (Cavalcante, 2005, p. 56).

A aprendizagem é um processo que se concretiza pelas relações afetivas entre professor/aluno, assim sendo, quanto mais a criança se sente envolvida nestas relações, mais amplia sua capacidade de aprendizagem e desenvolvimento. A afetividade compreendida como os processos de afetação do ser com o intuito pedagógico deve estar alicerçada em ações intencionais, pautadas no conhecimento prévio das necessidades do educando. Neste sentido, é imprescindível planejar as ações de maneira a atender a complexidade provenientes das interações vivenciadas pelos sujeitos envolvidos no processo ensinoaprendizagem.

o ato de planejar exige aspectos básicos a serem considerados. Um primeiro aspecto é o conhecimento da realidade daquilo que se deseja planejar, quais as principais necessidades que precisam ser trabalhadas; para que o planejador as evidencie faz-se necessário fazer primeiro um trabalho de sondagem da realidade daquilo que ele pretende planejar, para assim, traçar finalidades, metas ou objetivos daquilo que está mais urgente de se trabalhar (Oliveira, 2007, p. 21).

O planejamento permite que a ação afete a criança intencionalmente e conscientemente, considerando as peculiaridades de cada fase de seu desenvolvimento, de modo a influenciar incisivamente na sua aprendizagem. Mediante essa segunda unidade de registro, obtemos que as professoras admitem que a afetividade é importante para o processo de aprendizagem da criança e compreendem que o afeto se constrói pelas relações de carinho, respeito e diálogo, promovidas pelo professor em sala de aula.

As professoras afirmam que a afetividade promove melhorias no ensino da educação infantil, visto que influencia diretamente na aprendizagem da criança e no seu desenvolvimento pleno. Entendem que atividades lúdicas e dinâmicas trabalhadas por meio da afetividade são importantes porque fortalecem as relações entre professor/aluno, promovem a socialização e interação da turma e isso influencia diretamente na aprendizagem da criança. Também, compreendem que o aluno deve ser estimulado a desenvolver suas emoções positivas, aprender sobre valores de respeito, solidariedade, conviver em grupo, entre outros, pois isso possibilitará seu desenvolvimento pleno. As professoras entendem que todas essas relações e interações devem ser pautadas no diálogo, respeito e cordialidade, porque isso gera confiança e facilita a construção de novos saberes.

Todas as professoras destacaram que a afetividade mantém relação com a aprendizagem e que esta relação se dá pelo envolvimento da criança com o professor e com o meio. Mencionam a importância de proporcionar um ambiente afetuoso e tranquilo, pois acreditam que a qualidade do ambiente influencia diretamente no processo de aprendizagem. Foram unanimes em afirmar que constroem relações afetivas em suas atividades cotidianas e que essas relações se desenvolvem no campo da espontaneidade. 


\section{considerações finais}

Este artigo buscou explicar a correlação entre aprendizagem e afetividade, sendo possível refletir sobre o tema através da contribuição de teóricos como Wallon, Vygotsky, Piaget, Paulo Freire, dentre outros, o que nos fez pensar sobre a importância das relações entre o professor e o aluno, especificamente na educação básica em creche, onde a criança comunica-se expressivamente pelas emoções e, por isso, precisa ser compreendida e afetada a partir de suas reais necessidades.

Conforme inferimos, a relação professor/ aluno deve ser pautada tanto pelas condições físicas de um espaço capaz de atender as necessidades da criança, como também, pela capacidade do professor estabelecer diálogos, desenvolver a empatia para melhor compreender a linguagem emocional da criança e afetá-la sem as marcas de uma relação autoritária e coercitiva, mas sim pelas marcas da alegria e entusiasmo que criam condições para a criança se desenvolver mais rapidamente e integralmente.

\section{referências}

Bicudo, M. A. V. (2011). Pesquisa qualitativa segundo a abordagem fenomenológica. São Paulo: Cortez.

Cavalcante, M. (2005). Como criar uma escola acolhedora. Nova Escola, 180(4), 52-57.

Cohen, R. H. P. (2014). Apostila de psicomotricidade. Universidade Federal do Rio de Janeiro: Rio de Janeiro/RJ, 1-17.

Couto Júnior, D.R., Pocahy, F., \& Oswald, M. L. (2018). Crianças e infâncias (im)possíveis na escola: dissidências em debate. Revista Periódicus, 1(9), 55-74.

Cunha, A. E. (2008a). Afetividade na prática pedagógica: educação, TV e escola. Rio de Janeiro: Wak Editora.

Cunha, A. E. (2008b). Afeto e aprendizagem, relação de amorosidade e saber na prática pedagógica. Rio de Janeiro: Wak Editora.

Davis, C., \& Oliveira, Z. (1990). Psicologia na educação. São Paulo: Cortez.

Freire, P. (1996). Pedagogia da autonomia: Saberes necessários à prática educativa. São Paulo: Paz e Terra.
Garcia, R. M. (2020). A constituição de corpos e infância durante as aulas de Educação Física escolar. In W. K. F. Santana, \& E. L. Silveira (Orgs.). Educação: entre saberes, poderes e resistências, São Carlos: Pedro \& João Editores, 10-21.

Garcia, R. M., Pereira, E. G. B. (2019). Reflections about the film "The Wild Child" (1970) through Piaget and Vygotsky perspectives. Journal of Humanities and Education Development, 1(4), 179-185.

Gonçalves, M. F. C. (Org). (2003). Educação escolar: identidade e diversidades. Florianópolis/SC: Insular.

Oliveira, Z. (2007). Educação Infantil: fundamentos e métodos. São Paulo: Cortez.

Piaget, J. (1959). A Linguagem e o pensamento da criança. Rio de Janeiro: Fundo de Cultura.

Piaget, J. (1983). Psicologia da inteligência. (2a ed., N. C. Caixeiro, Trad.) Rio de Janeiro: Zahar.

Richardson, R. J. (2008). Pesquisa social: métodos e técnicas. São Paulo: Atlas.

Rizzo, G. (2006). Creche: organização, currículo, montagem e funcionamento. Rio de Janeiro: Bertrand Brasil.

Rodrigues, M. (1976). Psicologia educacional: uma crônica do desenvolvimento humano. São Paulo: Mc Graw-Hill do Brasil.

Roncarati, M. (2012). Afetividade na creche: reflexões sobre suas emoções. São Paulo: Editora Dimensão.

Vygotsky, L.S. (2003). Psicologia pedagógica. Porto Alegre: Artmed.

Wallon, H. (1986). As origens do pensamento na criança. São Paulo: Manole.

Wallon, H. (1995). Psicologia e educação da infância. Lisboa: Estampa.

Wallon, H. (2007). A evolução psicológica da criança. São Paulo: Martins Fontes.

recebido em 31/08/2020 aceito em 18/12/2020 